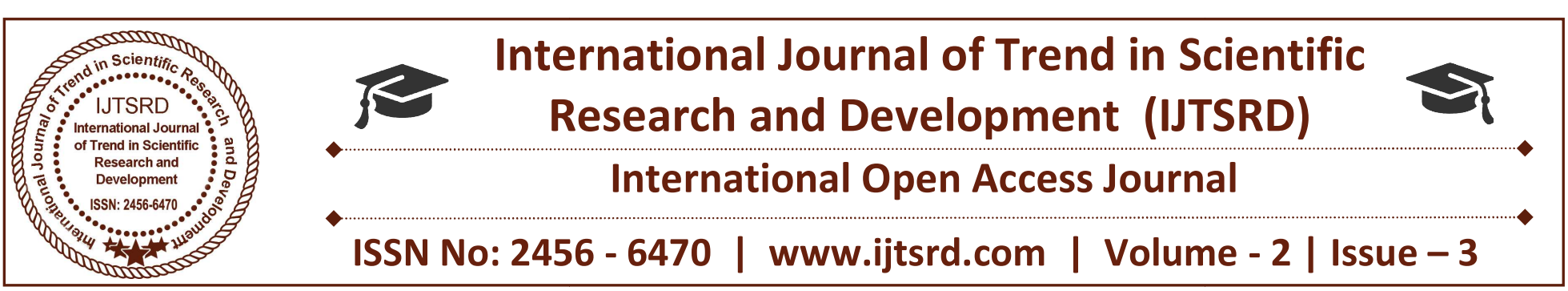

\title{
Optimization of Trimming and Piercing Operations by Introducing a New Tool
}

\author{
Benin S. R, A. Jacob Moses, Renjin J Bright \\ Assistant Professor, Department of Mechanical Engineering, \\ Jeppiaar SRR Engineering College, Chennai, Tamil Nadu, India
}

\begin{abstract}
To survive in business with profit in between crises and competition, we need to increase cost of the product. Unfortunately that is not an option to survive in business with great profit due to competition. The main option is to reduce the manufacturing cost with same quality. In this situation we have to look upon the process planning. From this I have concluded that combining two process into one could achieve what we want that is reducing process into lean, it reflect in
\end{abstract} cost.

The various stage tools are TRIMMING and PIERCING operation is done by using in two mechanical presses at individual operator, the production efficiency is less \& Tool cost is high.

For this problem, I am planning to do new design of Combination tool.

By designing of combination tool, following will be achieved to reduce the production cost which is our main Aim.

1) Setup time will be reduced

2) Cycle time will be reduced

3) One Man power will be eliminated

4) One Press Machine will be eliminated

5) Tooling cost will be reduced

6) Overall Operating cost \& cost per component will be reduced.

This project focusing on Stage reduction by new combination Tool design \& Tool manufacturing for the Trimming and Piercing tool operation .This Tool will be called as TRIM \&PIERCING TOOL. The

product is Automobile BRAKE BACK PLATE for the customer of FORD Automotive.

Keywords: Trimming; Piercing; cost reduction; New back plate;

\section{INTRODUCTION}

\section{A. PRODUCT INTRODUCTION}

"Press working is a chip-less manufacturing process by which various components are made from a sheet metal as a result of plastic deformation and shearing of source material in the cold state, by the special tool, referred as a press tool."

Press tool is an assembly of various elements such as top plate, bottom plate, punch holder, back plate etc, specially designed to fabricate a specific sheet metal component.

A wide Varity of operation can be performed on sheet metal by press working. These operations can be classified into cutting and non-cutting operations. The cutting operation involves the separation of parts from the source material. Blanking, piercing, trimming are some of the examples of cutting operation. In non-cutting operation, parts are obtained by plastic deformation of source material such as bending, forming, drawing etc.

\section{B. BRAKE LAYOUT}

Drum brakes are used in most heavy duty trucks, some medium and light duty trucks, and few cars, dirt bikes, and ATVs. Drum brakes are often applied 
to the rear wheels since most of the stopping force is generated by the front brakes of the vehicle and therefore the heat generated in the rear is significantly less. Drum brakes allow simple incorporation of a parking brake.

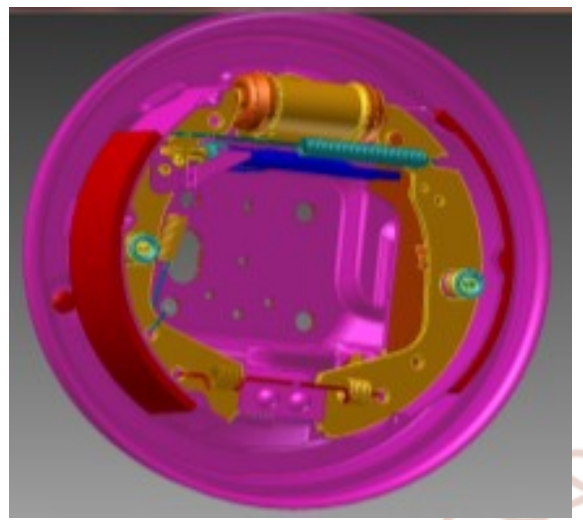

Fig: 1 Brake layout

\section{PRODUCT PARTS}

Some of the major components of the drum brake assembly are the back plate, the brake drum and shoe, the wheel cylinder, various springs and pins etc.

\section{Back plate}

The back plate serves as the base on which all the components are assembled. It attaches to the axle and forms a solid surface for the wheel cylinder, brake shoes and assorted hardware. Fig 2 shows the back plate.

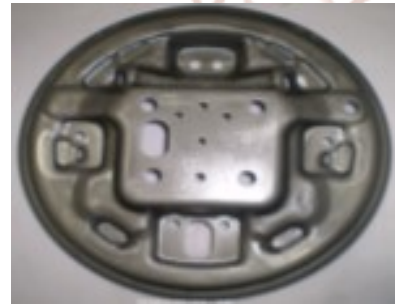

Fig: 2 Back plate

Since all the braking operations exert pressure on the back plate, it needs to be very strong and wearresistant. Levers for emergency or parking brakes, and automatic brake-shoe adjuster were also added.

\section{Wheel cylinder}

One wheel cylinder is used for each wheel. Two pistons operate the shoes, one at each end of the wheel cylinder. When hydraulic pressure from the master cylinder acts upon the piston cup, the pistons are pushed toward the shoes, forcing them against the drum. When the brakes are not being applied, the piston is returned to its original position by the force of the brake shoe return springs.

\section{Brake shoe}

Brake shoes are typically made of two pieces of sheet steel welded together. The friction material is either reverted to the lining table or attached with adhesive. The Fig 1.4 shows the Brake shoe assembly, Materials which make up the brake shoe include, friction modifiers powdered metal such as lead, zinc, brass, aluminum and other metals that resist heat fade, binders, curing agents and fillers such as rubber chips to reduce brake noise.

\section{PRESS TOOL OPERATIONS}

The press tool operation different stages will be there
1. SHEARING
2. BLANKING
3. PIERCING
4. TRIMMING
5. COINNING
6. FORMING
7. DRAWING

\section{SHEARING}

The name of the shearing stands for the method of cutting sheets or stock without forming of chips the material is stressed in a section, which lies parallel to the forces applied. The forces are applied either by means of shearing blades or punch and die.

\section{BLANKING}

A blanking tool produces a blank by cutting the entire periphery in one simultaneous operation.

\section{PIERCING}

Piercing dies pierce holes in stampings. There are two principle reasons for piercing holes in a separate operation instead of combining piercing with other operations:

1. When a subsequent bending, forming, or drawing operating would distort the previously pierced hole or holes.

2. When the edge of the pierced hole is too close to the edge of the blank for adequate strength in the die 
section. This occurs in combination tools in which piercing and blanking are done simultaneously.

\section{TRIMMING}

Trimming tools cut away portions of formed or drawn work pieces that have become wavy and irregular. This condition occurs because of uneven flow of metal during forming operations. Trimming removes this unwanted portion to produce square edges and accurate contours.

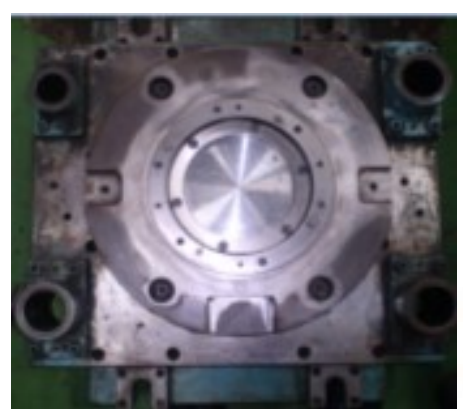

Fig: 3 Bottom tool

\section{COINING}

Coining is the operating of pressing material in a die so that it flows into space in the detail of the die face. Coining differs from embossing. In coining the metal flows, whereas in embossing the metal does not change in thickness to a great extent.

\section{FORMING}

The operation of forming is similar to bending except that line of bend is curved instead of straight and plastic deformation in the material is more severe.

\section{DRAWING}

The operation of drawing is similar to forming although there is more sever plastic deformation in the material. The difference between the two occurs in the extent of the form. Consider a drawn cup such as a metal ringing up. The material does not extend completely around to surround a space, even though the formed contour may be quite intricate

\section{E. MATERIALS AND METHODS}

A shearing operation that removes uneven section from the top of the rim previously worked part. Trimming operation typically follows drawing operation of sheet metal.

The bottom tool of trimming assembled in bottom bolster .and stripper plate. Punch holder, punch, backing plate. In the condition the punch is clearance part. The top tool of trimming assembled in top bolster. And die holder, die, and backing plate. In the condition the Die is master part.

\section{TRIMMING TOOL}

The all operation are shearing, drawing and coining completed in before trimming operation

\section{TRIMMED COMPONENT}

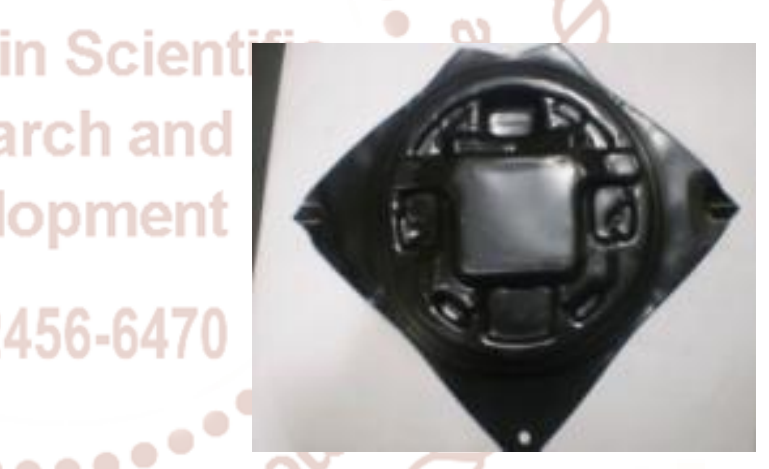

Fig: 5 Before trimming

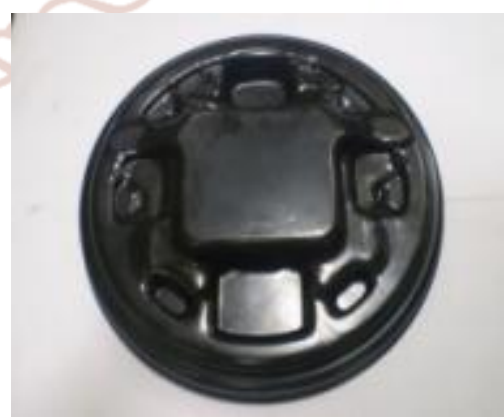

Fig: 6 After trimming

Piercing involves cutting of clean hole with resulting scrap slug. The operation is often called piercing in general the term piercing is used to describe die cut hole regardless of size and shape. Piercing is performed in a press with the die. The tool is used to 
International Journal of Trend in Scientific Research and Development (IJTSRD) ISSN: 2456-6470 pierce the holes as secondary tool such as after bending of component etc.

The bottom tool of piercing assembled in bottom bolster .and die holder locater, die inserts. In the condition the die is clearance part.

\section{PIERCING TOOL}

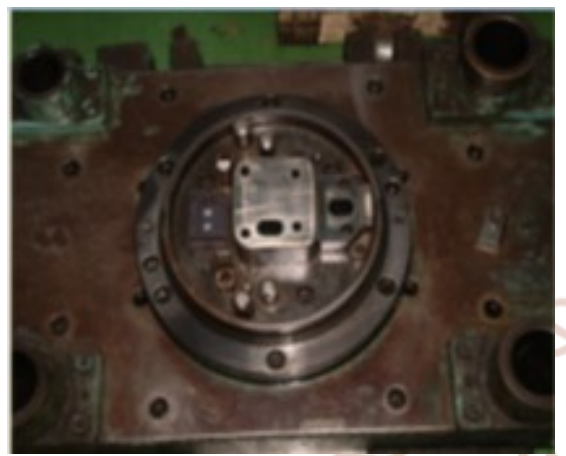

Fig: 7 Bottom tool

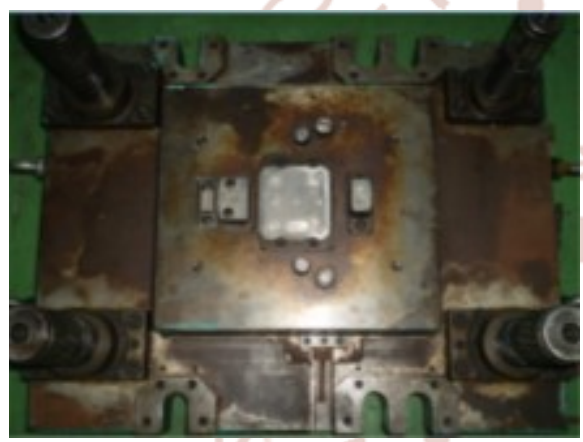

Fig:8 Top tool

The all operation are shearing, drawing and coining trimming completed in before piercing operation

\section{PIERCING COMPONENT}

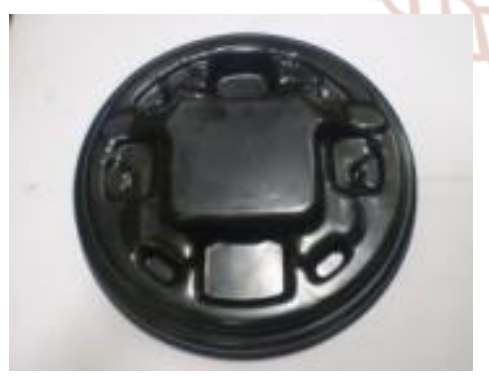

Fig: 9 Before piercing

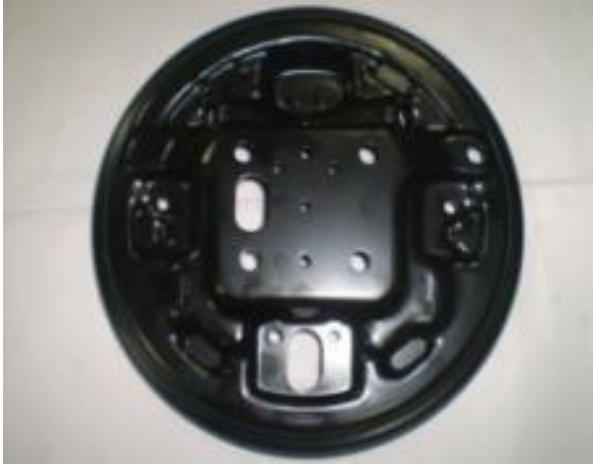

Fig: 10 After piercing

This work eliminates the two stage operations and improve the productivity.

\section{F. TIME AND COST ANALYSIS}

The component rate included in machine hour rate \& tooling cost. The machine hour rate included in machine rate, rent of machine area, building investment, energy $\%$ of power, insurance $\%$ of total investment labor cost in direct \& indirect, consumable, tooling per price, total operating cost.

Table: 1 Back plate price detail

\begin{tabular}{|c|c|c|c|c|c|c|c|}
\hline \multicolumn{2}{|r|}{ Operation } & \multicolumn{3}{|c|}{ Machine } & \multirow{2}{*}{\begin{tabular}{|c|} 
Man \\
Required \\
(in Nos)
\end{tabular}} & \multirow[b]{2}{*}{ Hr. rate } & \multirow{2}{*}{$\begin{array}{c}\text { conponers } \\
\text { Cost per } \\
\text { price }\end{array}$} \\
\hline $\begin{array}{l}\text { Seq. } \\
\text { No. }\end{array}$ & Descripoion & $\begin{array}{l}\text { Press } \\
\text { (ton's) }\end{array}$ & $\begin{array}{l}\text { Press Cost } \\
\text { with } \\
\text { instalation } \\
\text { (In Labts) }\end{array}$ & $\begin{array}{l}\text { Motor } \\
\text { HP }\end{array}$ & & & \\
\hline 1 & Trimming & 250 & 1200 & 60 & 1 & 160 & 78 \\
\hline 2 & Piercing & 250 & 600 & 40 & 2 & 160 & 6.3 \\
\hline
\end{tabular}

3D MODEL OF NEWLY FORMED TOOL

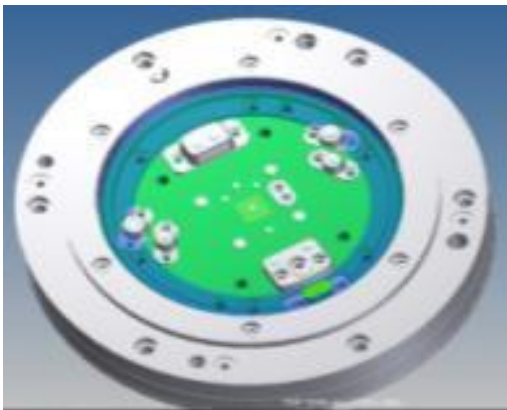

Fig: 11 3D model of top tool 


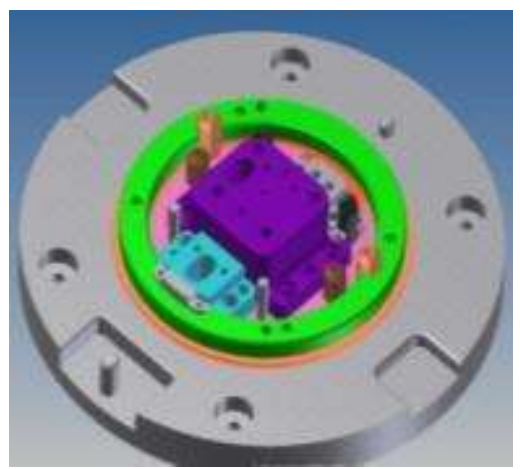

Fig: 12 3D model of bottom Tool

The model is created in inventor software. First draw the rough sketch due to maintain in shut height then draw the 2D drawing in AutoCAD software. Then the detail view created in 3D model due to alignment problem, assembly problems at some of details create for programming purpose in $\mathrm{CNC}$ machine.

\section{COST COMPARISON}

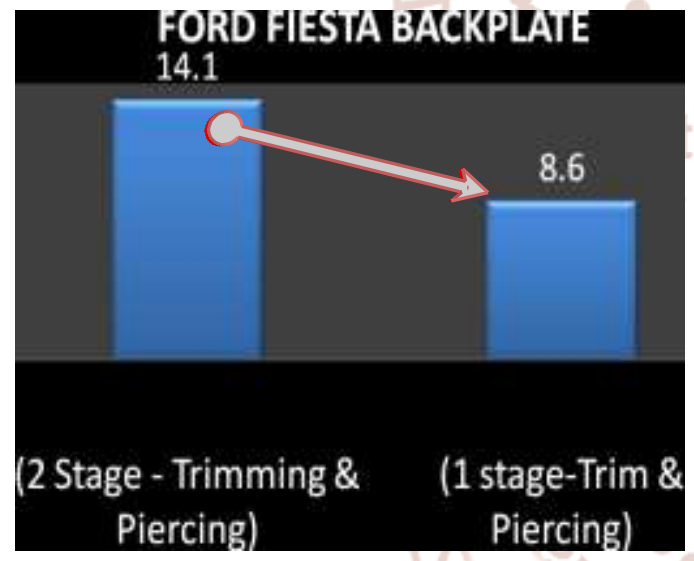

\section{BENEFITS}

1. Reduce run out problem in locating hole to outer diameter,

2. First off inspection time is less,

3. Tool setting time reduced,

4. Reduce Tool investment cost,

5. Reduced man power,

6. Increased productivity

\section{G. SUMMARY}

With this project, various stages of operations such as Trimming and Piercing are integrated in to one tool and it is now a single operation which can be done by an individual operator.
As reduction of multi stage operation, requirement of machine and man hours getting reduced and the production efficiency is improved compare to the earlier process. Tool cost occurring in the Trimming and Piercing tool is reduced significantly. To reduced lead time of the process and reduced run out problem in locating hole to outer diameter of the back plate. During setup tool setting time reduced and tool investment cost also reduced. The effect of both the tool combining operation productivity increased. The 3D model detail to manufacture in $3 \mathrm{D}$ programming used in unigraphics software.

\section{H. CONCLUSIONS}

The conclusion is to high light the issues in the manufacturing process. And we changed the combined process instead of separate operation. The usage of this tool reduced the tool manufacturing cost and during part changeover tool setup time also reduced. Reduce the man power and machine hour rate by using combine tool increased the productivity by reduced of cycle time. Reduced troubleshoot time during operation.

\section{REFERENCES}

1) David Smith," Die Design Handbook", 3rd Edition, SME 1990, page no, 315-510

2) Ernest Perry, "Press tool making", Read Books, 2008, page.No.32-98.

3) John A. Waller, "Press Tools \& Presswork", the University of California 3, illustrated, revised Portcullis Press, 1991, page.No.241-316.

4) Pearce R, "Sheet Metal Forming" Springer, 1991 page.no.131-190

5) 5) Schuler GmbH, "Metal Forming Handbook" Edition 1, Springer Berlin Heidelberg 1998, page no, 211-298

6) William Francis Walker, "Guide to press tool design", the University of Wisconsin, NewnessButterworth, 1970, page no.122-190 